\title{
Макєঠovıкá
}

Tó 37 (2008)

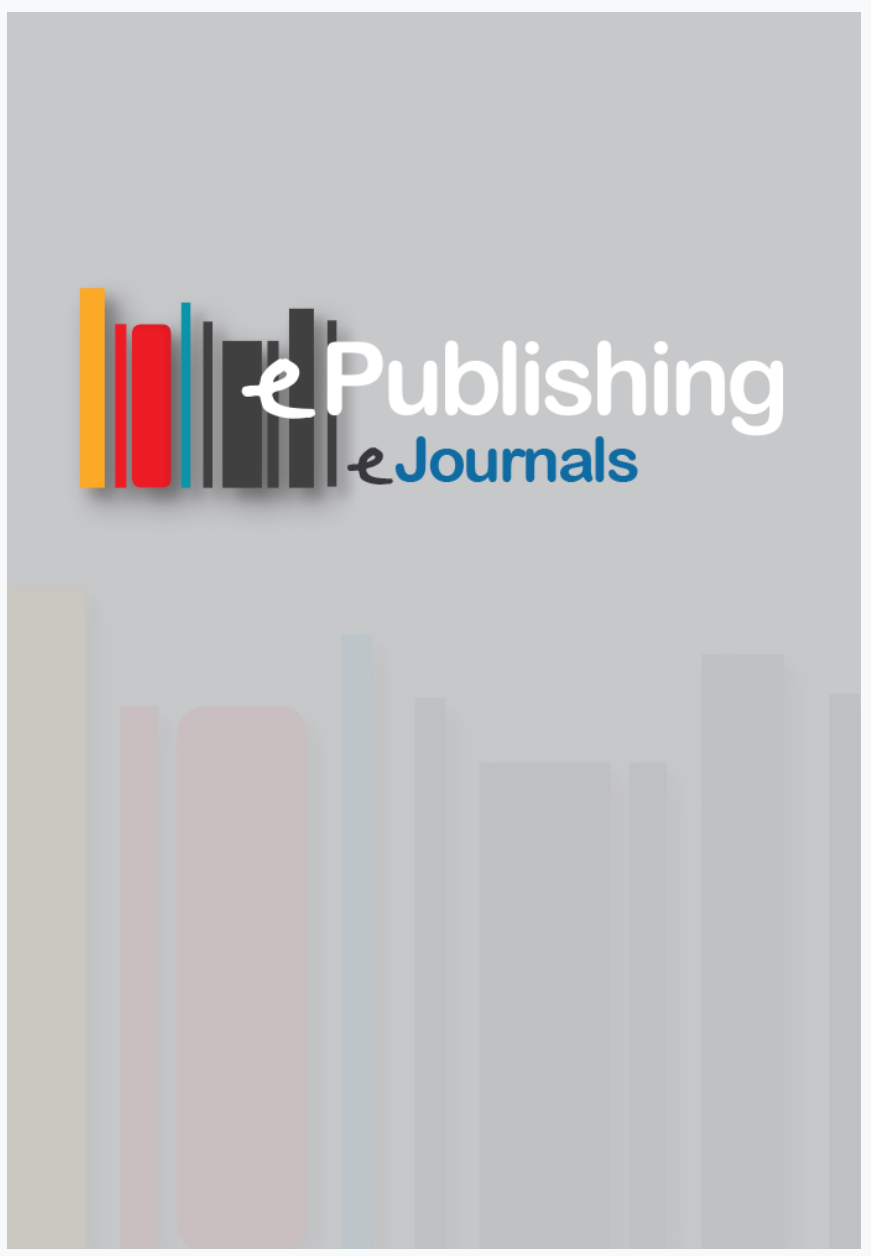

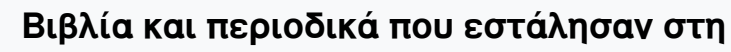

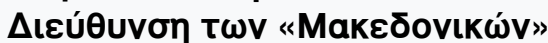

\section{Makedonika Makedonika}

doi: $10.12681 /$ makedonika.57

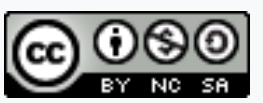

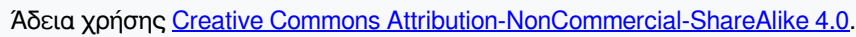

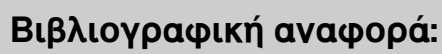

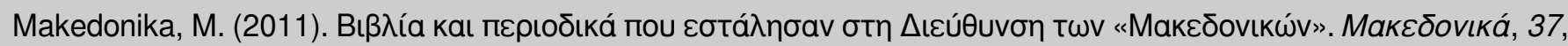
307-310. https://doi.org/10.12681/makedonika.57 


\title{
BIB $\Lambda$ IA KAI ПEPIO $\triangle$ IKA \\ ПOY E $\Sigma$ TA $\Lambda H \Sigma$ AN $\Sigma$ TH $\Delta$ IEY $\Theta Y N \Sigma H$ T $\Omega N$ «MAKE $\Delta$ ONIK $\Omega N »$
}

\author{
$\mathrm{A}^{\prime} \mathrm{BIB} \Lambda \mathrm{IA}$
}

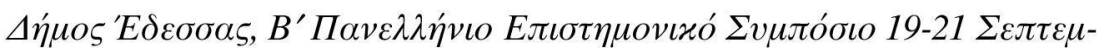

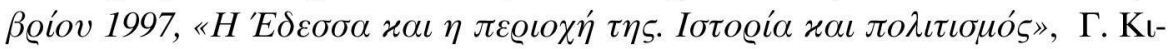

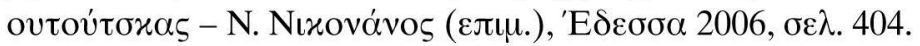

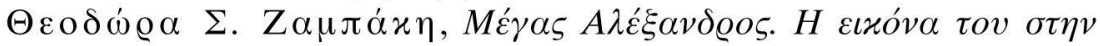

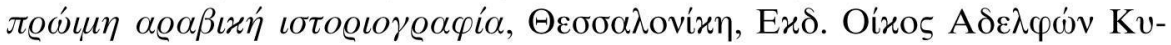

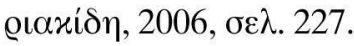

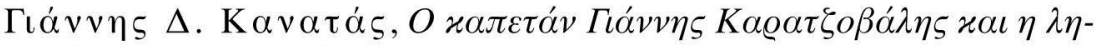

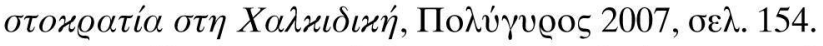

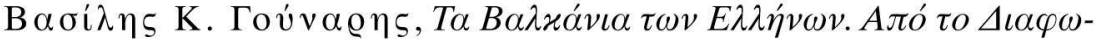

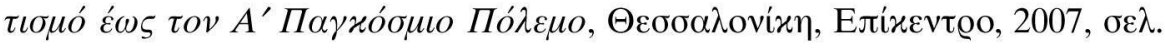

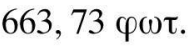

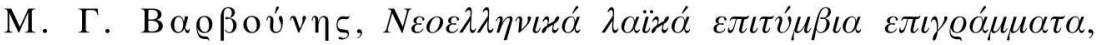

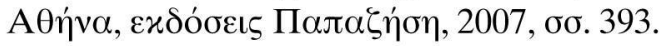

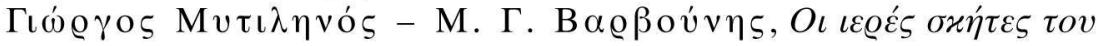

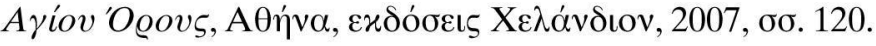

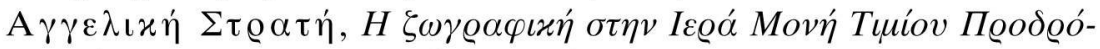

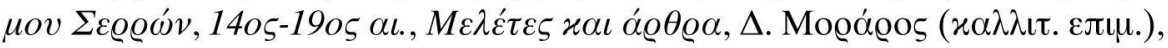

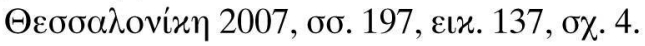

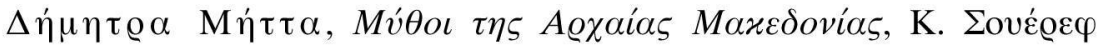

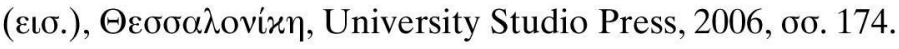

\section{$\mathrm{B}^{\prime}$ ПЕPIO $\triangle \mathrm{IKA}$}

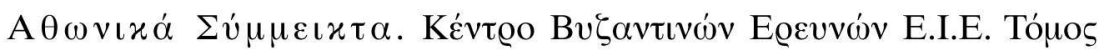
10 (2007), A $\theta \dot{v} v \alpha$.

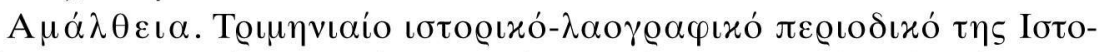

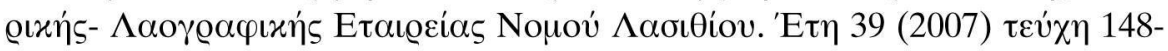

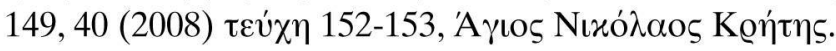

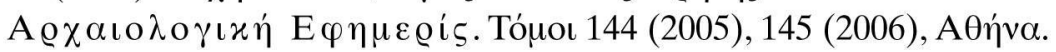

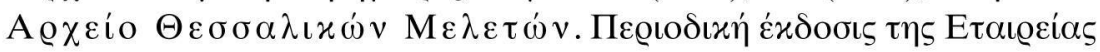

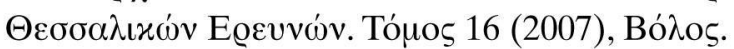

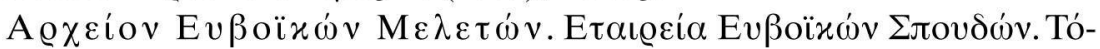
$\mu \circ \varsigma \Lambda \Sigma T^{\prime}(2005-06), A \theta \eta \dot{v} \alpha$. 


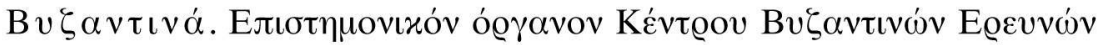

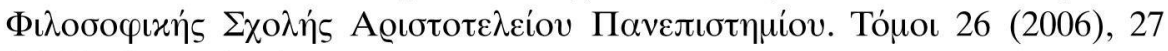

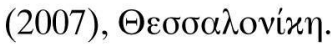

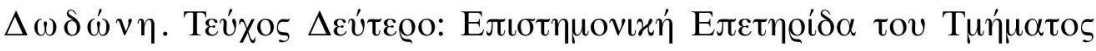

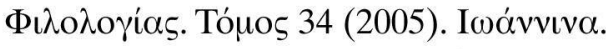

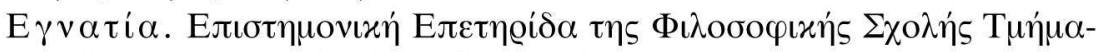

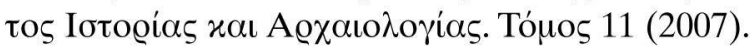

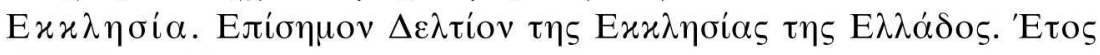

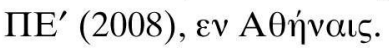

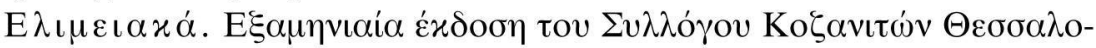

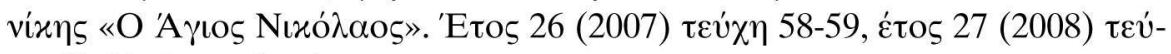

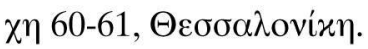

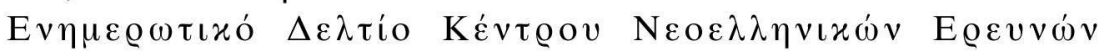

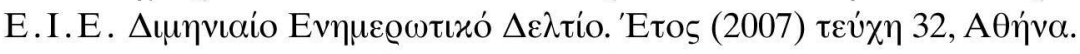

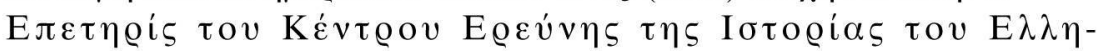

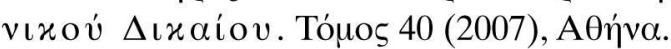

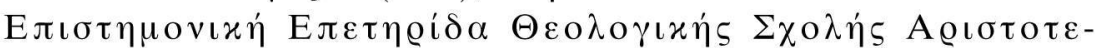

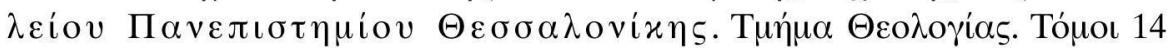

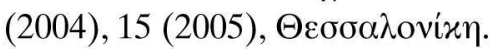

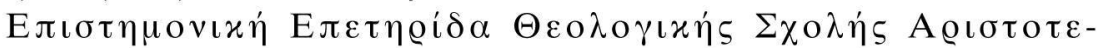

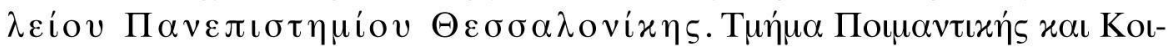

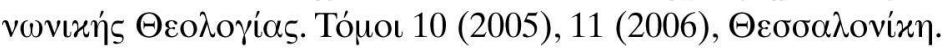

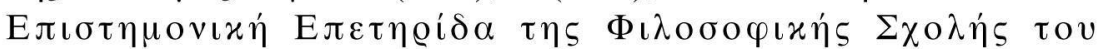

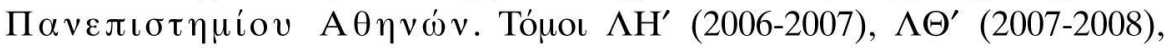
A $\theta \dot{\eta} v \alpha$.

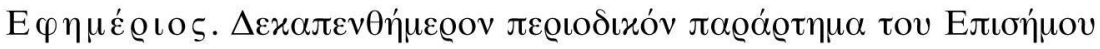

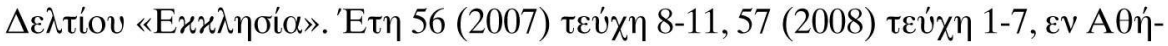
vars.

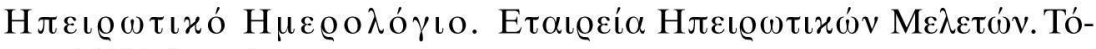

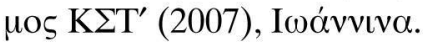

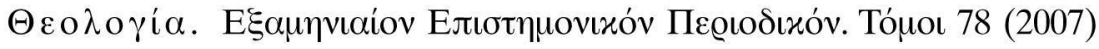

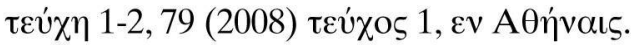

$\Theta \varepsilon \sigma \sigma \alpha \lambda \iota x o ́$ H

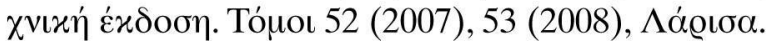

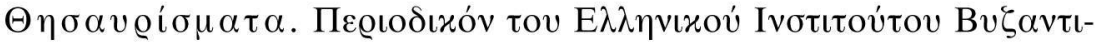

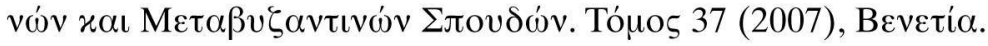

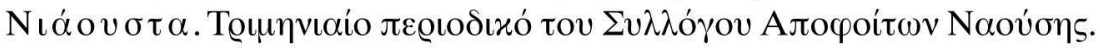

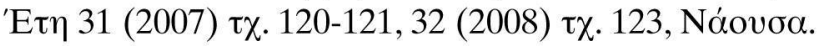

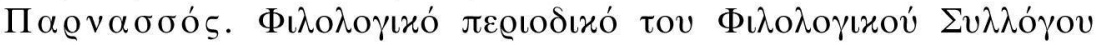

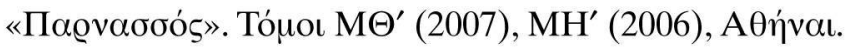




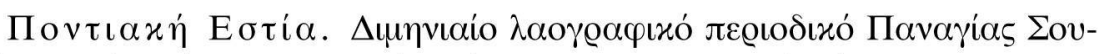

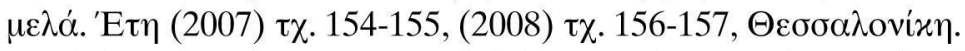

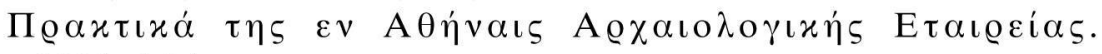

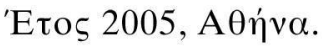

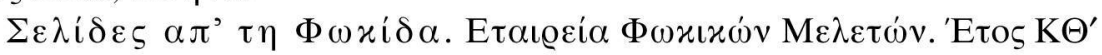

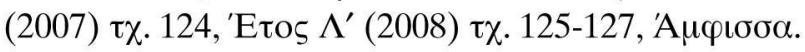

Analecta Bollandiana. Revue critique d'hagiographie trimestrielle. Tome 126 (2007) Fasc. 1-2, Bruxelles.

The Annual of the British School at Athens. Year (2007) no 102, London.

A pulum. Acta Musei Apulensis: Arheologie, Istorie, Etnografie. Vol. 44 (2007), Alba Iulia.

Bulgarian Historical Review. Research Quarterly Organ of the United Centre for History at the Bulgarian Academy of Sciences. Year 34

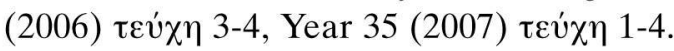

Byzantine and Modern Greek Studies. Centre for Byzantine, Ottoman and Modern Greek Studies, University of Birmingham. Vol. 32 (2008).

Études Balkaniques. Académie Bulgare des Sciences. Institut d'Études Balkaniques. Année 43 (2007) no 2-4, Année 44 (2006) no 1-2, Sofia.

Hesperia. Journal of the American School of Classical Studies at Athens. Vol. 76 (2007) no 2-4, Vol. 77 (2008) no 1-2, Athens.

Historical Abstracts. Bibliography of the World's Historical Literature. Vol. 58 (2007), Santa Barbara, California.

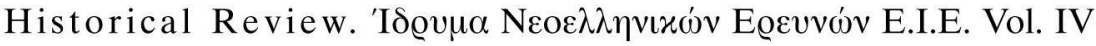
(2007) $A \theta \eta \dot{v} \alpha$.

Jahrbuch der Österreichischen Byzantinistik. Österreichischen Akademie der Wissenschaften. Band 57 (2007), Wien.

Journal of Hellenic Studies. Vol. 126 (2006), 127 (2007), London.

Makedonski Pregled. Spisanie za Nauka, literarura i Obštestven život. Godina 30 (2007) kn 2-4, Makedonskijat Naucen Institut, Sofija.

Mélanges de l'École Française de Rome (MEFRA). Tome 119 (2007) no 1, Rome.

Mittheilungen des Deutschen Archäologischen Instituts Athenische Abteilung. Band 121 (2006), Berlin.

Revue des Études Grecques. Publication trimestrielle de l'Association pour l'Encouragement des Études Grecques. Tome 120 (2007) no 2, Tome 121 (2008) no 1, Paris. 
Revue des Études Sud-Est Européennes. Publié par l'Académie des Sciences Sociales et politiques. Institut d'Études Sud-Est Européennes. Tome 45 (2007) no 1-4, Bucuresti.

Rivista di Archeologia. Publicazione annuale diretta da Gustavo Traversari. Anno XXX (2006), Venezia.

Vestnik Drevnej Istorii. Rossijskaja Akademija Nauk. Institut Vseobsej Istorii. Vol. (2007) no 3-4, Vol. (2008) no 1-2, Moskva. 